\title{
Study on Management and Application System of Patent Knowledge based on TRIZ*
}

\author{
Gao Changqing \\ School of Mechanical Engineering \\ University of Jinan \\ Jinan, China \\ me_gaocq@ujn.edu.cn \\ Sun Jianhua \\ School of Mechanical Engineering \\ University of Jinan \\ Jinan, China \\ 695662900@qq.com
}

\author{
Chen Wei \\ School of Mechanical Engineering \\ University of Jinan \\ Jinan, China \\ 95671545@qq.com \\ Zhao Fang \\ School of Mechanical Engineering \\ University of Jinan \\ Jinan, China \\ me_zhaof@ujn.edu.cn
}

\begin{abstract}
Innovation design requires a lot of knowledge. The study on how to effectively store and manage existing knowledge, how to realize sharing and representation of knowledge is of great significance. In this paper, we expressed the tacit knowledge in patent content based on TRIZ theory, established the mapping relationship between patent knowledge and TRIZ knowledge, and extracted conflict, principle, effect, function, standard solutions information from tacit knowledge. In order to support the process of product innovation, we established patent knowledge base and developed computer aided design system to manage and store and apply these knowledge.
\end{abstract}

Keywords-TRIZ; patent knowledge; innovation

\section{INTRODUCTION}

Theory of Inventive Problem Solving can be abbreviated to TRIZ, it was proposed by G.S.Altshuller who is the inventor of former Soviet union. and his group on the basis of analyzing and studying about nearly 2.5 million patents in the world ${ }^{[1]}$. Russian spelling is “задачрешения изобретательских задач". TRIZ is a set of theory system that searches technological innovation laws with method and tool based on knowledge specially patent knowledge ${ }^{[2]}$. Patent is a knowledge carrier that contains a rich set of information. According to statistics of the World Intellectual Property Organization, patents content contain about 90 95\% innovation achievement every year. If we can make the fullest use of these patent knowledge for technical innovation, $60 \%$ of the time and $40 \%$ of scientific research funds will be saved ${ }^{[3-4]}$. Computer aided innovation is an effective method which support the process of innovation design and shorten the cycles of invention activities with innovative-design methods and knowledge database tools $^{[5]}$.

Based on TRIZ theory to analyze the patent knowledge, build patent knowledge base and develop computer aided innovation design system. After transforming domain problem into standard problem, designers can directly get implementation case of relevant solutions from knowledge base. This contributes to the management, sharing and representation of knowledge, meanwhile saving the time of innovation and improving the efficiency of design.

\section{MAPPING OF PATENT KNOWLEDGE AND TRIZ KNOWLEDGE}

There are two types of patent knowledge: explicit knowledge and tacit knowledge ${ }^{[6]}$. The purpose of extracting tacit knowledge of patents is to support the process of innovation design and provide tools and knowledge base of problem solving. We can extract a large number of tacit knowledge correspond with TRIZ knowledge from patent content, as shown in TABLE I.

\section{Construction of PATEnT KnOWLEDGE BASE}

Extract tacit knowledge of patents to establish the model of patent knowledge base, as shown in Fig. 1. Establish patent class with the method of object-oriented to package patent information, which supported the management and representation of knowledge. 
TABLE I. $\quad$ EXTRACTING OF PATENT TACIT KNOWLEDGE BASED ON TRIZ

\begin{tabular}{|c|c|c|}
\hline Content of patent & TRIZ knowledge & Description of knowledge \\
\hline $\begin{array}{l}\text { Title;Abstract; } \\
\text { Description }\end{array}$ & Knowledge of describing problem & $\begin{array}{l}\text { Defects of current technology and technological problem } \\
\text { need to be solved }\end{array}$ \\
\hline Abstract; Claims & Knowledge of function on target & $\begin{array}{l}\text { Function on target of patent, such as what actions will } \\
\text { complete }\end{array}$ \\
\hline Description & Knowledge of conflict and principle & $\begin{array}{l}\text { Technology or physical conflict solved by patent, and the } \\
\text { corresponding invention or separation principle }\end{array}$ \\
\hline $\begin{array}{l}\text { Claims;Description; } \\
\text { Attached Drawing }\end{array}$ & Knowledge of effect and function & $\begin{array}{l}\text { The effect used in patent and the function realized because } \\
\text { of effect }\end{array}$ \\
\hline $\begin{array}{l}\text { Claims;Description; } \\
\text { Attached Drawing }\end{array}$ & $\begin{array}{c}\text { Knowledge of action and standard } \\
\text { solution }\end{array}$ & $\begin{array}{l}\text { Standard solution used in the patent, and harmful, lacking, } \\
\text { excessive actions solved because of standard solutions }\end{array}$ \\
\hline
\end{tabular}

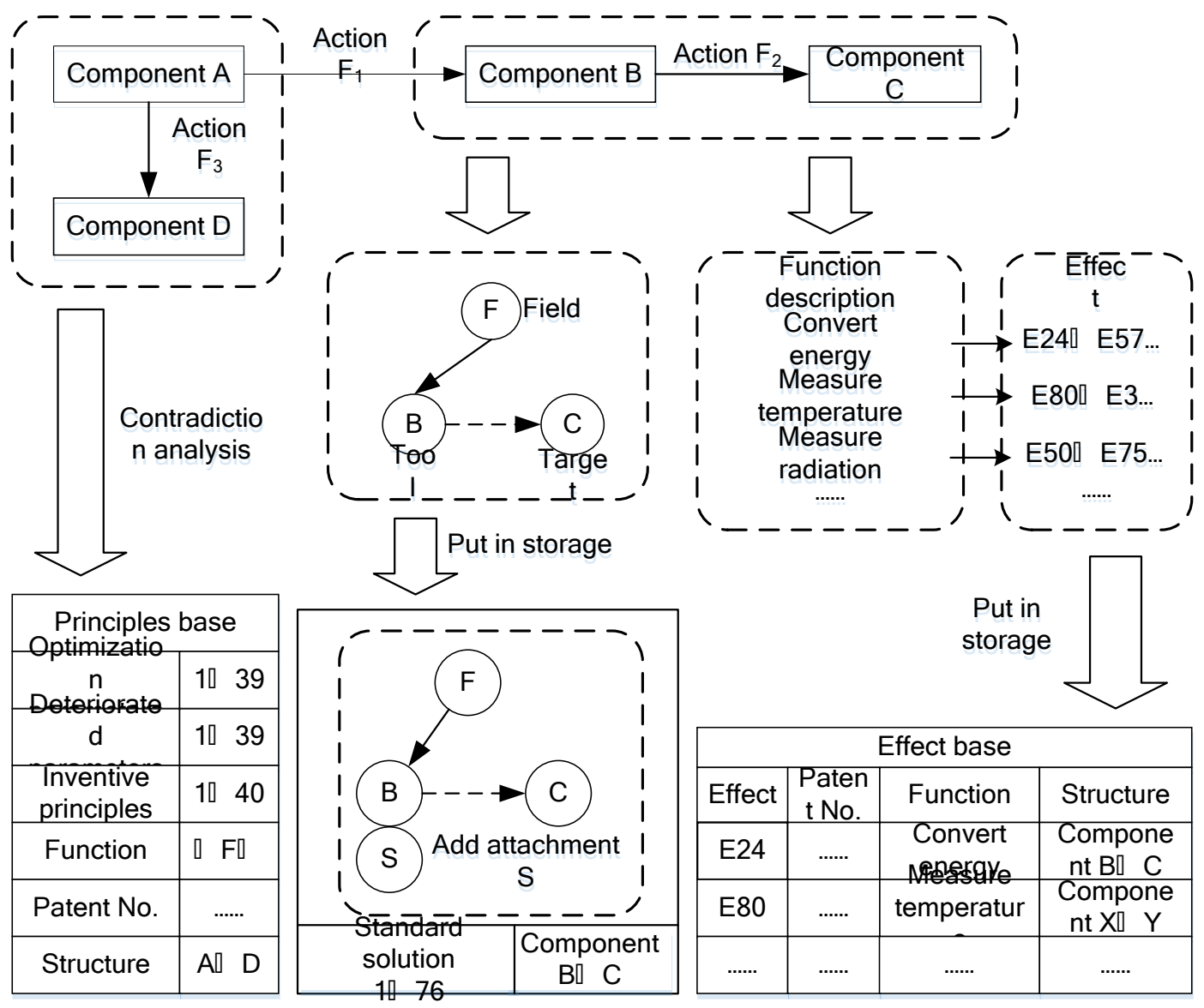

Fig. 1. The model of patent knowledge base

\section{COMPUTER Aided INNOVATION SYSTEM}

Innovation Engine is a CAI system developed in Chinese version based on TRIZ and patent knowledge base, as shown in Fig. 2 The development environment of system is Microsoft Windows 7 Ultimate, and development tools include Microsoft Visual Studio Ultimate 2012 (version 11.0.50727.1 RTMREL), Microsoft NET framework (version 4.5.50709) and Microsoft Office Access 2003.

In order to realize the system functions, we need to deal with the data relationships within the modules and interaction relationships between modules. These data relationships and interaction relationships are embedded in data base and rules base. Innovation engine is composed of patent base, tools base of TRIZ and functional modules. Patent data are collected through patent knowledge base online, such as USPTO, EPO, JPO, etc. Tools base of TRIZ included invention principles base, separation principles, scientific effect base, standard solutions base, etc. Functional modules included problem description, patent analysis, conflict solving, scientific effect, standard solutions, etc. The scientific effect module of Innovation Engine is shown in Fig. 3. 


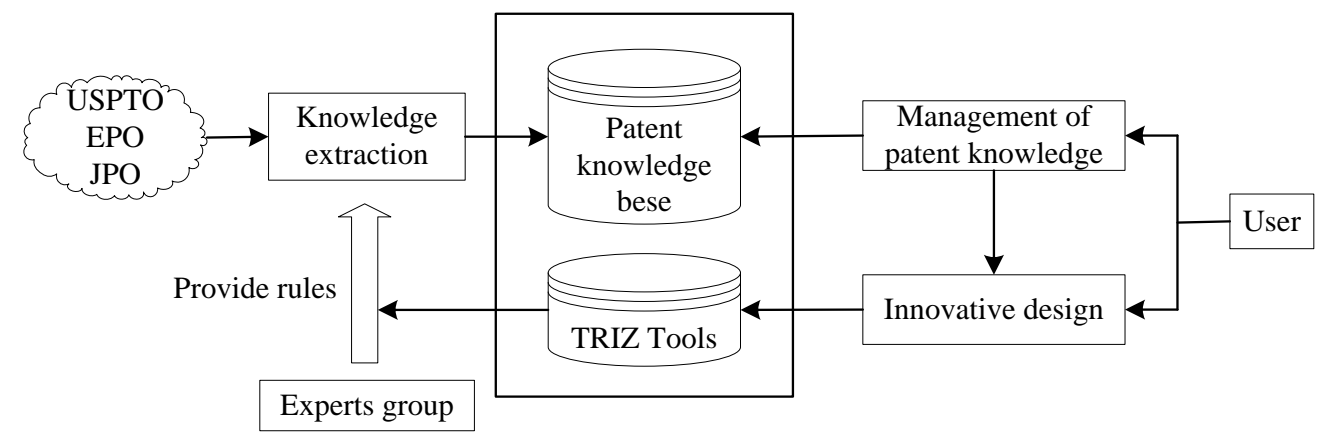

Fig. 2. Management system of patent knowledge

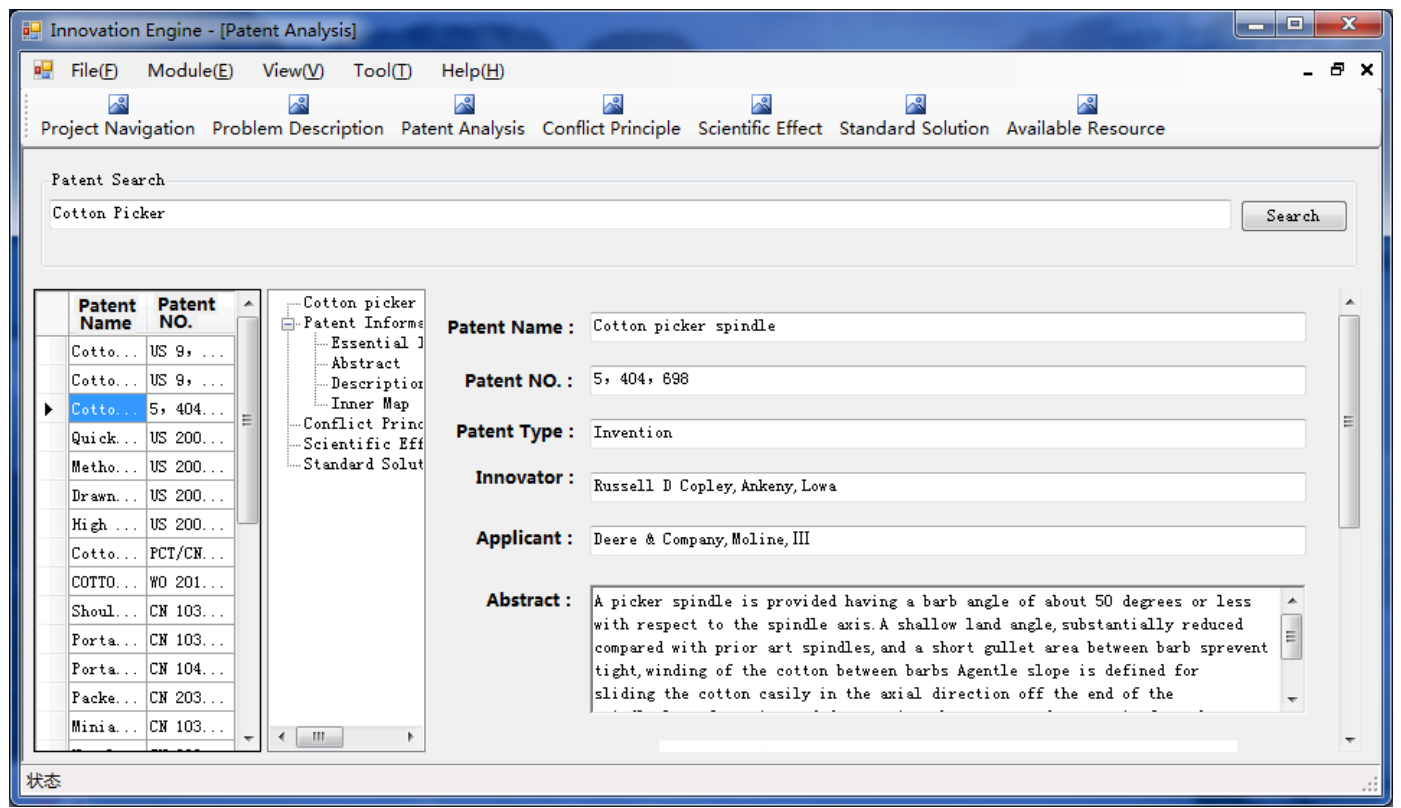

Fig. 3. Scientific effect module of Innovation Engine

\section{SUMMARY}

Knowledge representation is the core work of CAI, and the design experience of patent content is always represented in engineering cases. In this paper, we studied the extraction process of patent tacit knowledge based on TRIZ theory, established patent knowledge base with object-oriented approach. Then developed computer aided innovation system-Innovation Engine which have realized the management and representation of knowledge.

\section{ACKNOWLEDGMENT}

This work was financially supported by Innovation Project of Postgraduate Education of Shandong Province (SDYY15008) and Science and Technology Development Plan Project of Shandong Province (2014GGX106003).

\section{REFERENCES}

[1] Al' tshuller, G. S. (Genrikh Saulovich), Shulyak, Lev A, \& Rodman, Steven. (1999). The innovation algorithm: triz, systematic innovation and technical creativity. Aseanheartjournal Org.

[2] Chen, J. L., \& Chen, W. C. (2006). TRIZ Based Eco-Innovation in Design for Active Disassembly. Advances in Life Cycle Engineering for Sustainable Manufacturing Businesses.

[3] Sternitzke, C. (2010). Knowledge sources, patent protection, and commercialization of pharmaceutical innovations, 39(6), 810-821.

[4] Marchant, R. (2012). The global governance of knowledge: patent offices and their clients. World Patent Information, 34(29), 51-54.

[5] Leon, N. (2009). The future of computer-aided innovation. Computers in Industry, 60(8), 539-550.

[6] Kim, J. H., \& Choi, K. S. (2007). Patent document categorization based on semantic structural information. Information Processing \& Management, 43(5), $1200-1215$. 